\section{SOI: $1.1 /$ TAS DOI: $10.15863 /$ TAS International Scientific Journal Theoretical \& Applied Science}

\author{
p-ISSN: 2308-4944 (print) e-ISSN: 2409-0085 (online) \\ Year: $2015 \quad$ Issue: $05 \quad$ Volume: 25
}

Published: $30.05 .2015 \quad$ http://T-Science.org

SECTION 23. Agriculture. Agronomy. The technique.
Seisenbek Zaurbekovich Kazakbaev

Candidate of technical Sciences, correspondent member

RAM, carrying out the associate professor

Taraz innovative humanities university, Kazakhstan seisen58@mail.ru

Nurlan Syrymbayevich Karymsakov

Candidate of technical Sciences, Senior lecturer, Taraz state University named after M.Kh. Dulati,

Kazakhstan

karymsakov.nurlan@mail.ru

EImira Begaliyevna Madaliyeva

$\mathrm{PhD}$, associate Professor of Department of life Safety and basic military training,

Tarazsky innovative humanities university, Kazakhstan

Alexandr Nikolayevich Shevtsov candidate of technical sciences, member of PILA (USA), corresponding member of the Kazakhstan National

Academy of Natural Sciences, Department of «Mathematics», Deputy Director on Science of faculty of information technologies, automation and telecommunications, Taraz state University named after M.Kh. Dulati, Kazakhstan $\underline{\text { Shev_AlexXXXX@mail.ru }}$

\title{
GRAIN CASTER CLASSIFIER FOR POST-HARVEST PROCESSING OF GRAIN
}

Abstract: In the article the problems of creating high-performance and efficient machines on the basis of grain casters. Optimal parameters of technological operations for cleaning grain from various impurities. Development of the optimal design of pneumatic rotary classifier, which allows the combination of the transfer and primary processing preliminary drying of grain products.

Key words: grain caster, classifier, cleaning the grain.

Language: Russian

Citation: Kazakbaev SZ, Karymsakov NS, Madaliyeva EB, Shevtsov AN (2015) GRAIN CASTER CLASSIFIER FOR POST-HARVEST PROCESSING OF GRAIN. ISJ Theoretical \& Applied Science 05 (25): 8894.

Soi: http://s-o-i.org/1.1/TAS*05(25)18 Doi: crossef http://dx.doi.org/10.15863/TAS.2015.05.25.18

\section{УДК 681.869}

\section{ЗЕРНОМЕТАТЕЛЬ-КЛАССИФИКАТОР ДЛЯ ПОСЛЕУБОРОЧНОЙ ОБРАБОТКИ ЗЕРНА}

Аннотация: В работе рассматриваются проблемы по созданию высокопроизводительных и эффективных машин на базе зернометателей. Исследуются оптимальные параметры как технологической операции по очистке зерна от различных примесей, так и по разработке оптимальной конструкичи пневмороторного классификатора, позволяющче совмещение перегрузки и первичной переработки с предварительной сушкой зернопродуктов.

Ключевые слова: первичная очистка зерна, зернометатель-классификатор, очистка зерна.

Послеуборочная обработка зерна направлена на приведение убранной с полей зерновой массы в стойкое состояние при сохранении или улучшении качества принятого зерна. Полный цикл послеуборочной обработки включает в себя: приемку зерна и формирование партий, очистку от примесей, сушку и активное вентилирование. Приемку и обработку зерна целесообразно проводить на поточных технологических линиях, методом полного потока, не прерывая процесса вплоть до приведения зерна в стойкое при хранении состояние. Очистка зерна от примесей - важнейший прием в обработке зерна, существенно влияющий на стабильность качества хранящегося зерна; улучшающий качество партий зерна; повышающий эффективность 
работы и производительность технологического оборудования.

Послеуборочная обработка зерновых является одной из важнейших технологических операций, предопределяющая сохранность зерна. В отличие от существующей технологии очистки, основанной на применении большого набора громоздких, энергоёмких и дорогостоящих зерноочистительных машин и стандартных зерносушилок по предлагаемой технологии процесс обработки зерновых, состоит из трёх технологических операций: очистканормализация зернового вороха от крупных, мелких и лёгких примесей - половы, соломы, пыли и других лёгких включений, с одновременной осушкой поверхности зерна и его обеззараживанием.

До настоящего времени нет работ по созданию высокопроизводительных и эффективных машин на базе зернометателей и исследованию оптимальных параметров как технологической операции по очистке зерна от различных примесей, так и по разработке оптимальной конструкции пневмороторного классификатора, позволяющие совмещение перегрузки и первичной переработки, предварительной сушки зернопродуктов.

Применение предлагаемой техники и технологии позволяют получить экономический эффект 1,5 млн. тг. при переработке 1000 тонн зерна за счет снижения затрат от совмещения процесса приема и первичной переработки зерна. Использование предлагаемой технологии помимо очистки от вредных (вегетативных, составных частей ворохи зерна и сорных примесей) примесей сопровождается продувкой, т.е. предварительной сушкой, что положительно влияет на сохранность и на обеззараживание вредителей хлебных запасов.

Выгоды всех зернопроизводящих предприятий от внедрения «Зернометательклассификатора» заключаются в сокращении приведённых затрат в 2,5 раза на 1 тонну перерабатываемого зерна за счёт повышения производительности и эффективности очистки от крупных, металломагнитных, лёгких примесей и пыли, а также от вредителей хлебных запасов. Практически все крестьянские и фермерские хозяйства, хлебоприемные

зерноперерабатывающие предприятия получат выгоду от внедрения «Зернометательклассификатора» и технологии как минимум на 1600000 тенге за сезон уборки урожая, так как они надежны в эксплуатации, просты по конструкции, имеют низкие приведенные затраты. Учитывая, что проект направлен на создание и внедрение комплекса инновационной техники и технологии первичной очистки зернопродуктов от крупных и легких примесей, позволяющие повысить производительность сепараторов и эффективность переработки зерна, сокращение затрат на приемку и на обработку зерна, значительно уменьшающие зараженность зернопродуктов, создающие благоприятные условия для сушки и хранения зернопродуктов, перспективность выполнения НИОКР не вызывает сомнений.

Послеуборочная обработка зерна на току состоит из предварительной очистки, первичной очистки, временного хранения влажного зерна, сушки, вторичной очистки, сортировки. Свежеубранная зерновая масса, поступающая на зернотока, характеризуется высокой влажностью. Средняя влажность зерновой массы составляет 23-25\%, а в отдельные влажные годы и больше. Влажность сорных примесей в зерновом ворохе составляет 40-45\%, а иногда и значительно больше. При хранении такого зерна в нем идет перераспределение влажности между примесью и зерном, что приводит к увеличению влажности зерна. Это дополнительные затраты на сушку зерна. Влагообмен между сорняками и зерном завершается в основном в первые сутки хранения, поэтому предварительная очистка зерна должна проводиться немедленно, как только зерно поступило на ток. Чтобы успешно справляться с этой работой, производительность машин первичной очистки должна быть в 1,5 раза больше производительности комбайнового парка.

В настоящее время в условия рыночной экономики производители зерна (крестьянские и фермерские хозяйства), хлебоприёмные и зерноперерабатывающие предприятия РК и СНГ не в состоянии эффективно и своевременно производить послеуборочную обработку зернопродуктов, так как существующие ворохоочистители, зерноочистительные машины, пневмосепараторы, скальператоры громоздки, сложны, энергоемки с низкой пропускной и эксплуатационной способностью. Пневмоочистительные и обеспыливающие устройства не обеспечивают эффективной очистки зерна от легких примесей и пыли.

Предварительная очистка выполняется на машинах МПО-50 и СПО-100, входящих в состав комплекса 3АВ-50 и семенных линий, а также очиститель вороха самопередвижной ОВС-25, МC-4,5, . В процессе предварительной очистки семян должно выделяться не менее $50 \%$ сорной примеси зерна и вся соломистая органическая примесь. Используемые для предварительной очистки зерноочистительные сепараторы, ворохоочистители изношены и устарели, а их комплектующие изделия (сита, диски и др.) дорогостоящи.

Инновационные разработки относятся агропромышленному комплексу, к области приёмки и переработки зерновых продуктов, 
предназначенные для очистки зерна и зернистых продуктов от крупных, тяжелых, металломагнитных, легких примесей и пыли, а также для обеззараживания зернопродуктов.

Создание инновационной техники и технологии преследует проведение эффективной очистки зерна от крупных и легких примесей, а также от насекомых и клещей на токах крестьянских и фермерских хозяйств, что позволит снизить эксплуатационные расходы на приемку и обработку, повысить стойкость зерна при хранении и создать более благоприятные условия работы последующих транспортнотехнологических машин.

\section{Цель исследования:}

-создание и внедрение зернометательклассификатора для очистки зернопродуктов от крупных и легких примесей, позволяющая повысить производительность сепараторов и эффективность обработки зерна;

-сокращение приведённых затрат в 2,5 раза на 1 тонну обрабатываемого зерна, предотвратить зараженность зернопродуктов, произвести предварительную сушку зерна, создать благоприятные условия для сушки и хранения зернопродуктов.

Совмещение перекидки и первичной переработки зернопродуктов на токах крестьянских и фермерских хозяйствах позволит: производителью эффективно и своевременно производить очистку от примесей, сократить эксплуатационные расходы на приемку и обработку зерна, значительно снизить зараженность зерна вредителями хлебных запасов, создать благоприятные условия для сушки и хранения зерна. Применение предлагаемой техники и технологии позволяют получить экономический эффект 1,5 млн. тг. за счет снижения затрат от совмещения процесса приема и первичной переработки 1000 тонн зерна. Зернопроизводящие и хлебоприемные предприятия получат выгоду от внедрения «Зернометатель-классификатора», так как они надежны в эксплуатации, просты по конструкции, имеют низкие приведенные затраты и легко встраиваются в транспортные коммуникации линии приёма и первичной переработки зерна.

Новизной данного исследования является то, что пневмороторный классификатор установлен на зернометателе между скребковым конвейером и ленточным метателем, что позволит совместить перегрузочные операции с технологическими, как очистка зерна от крупных, металломагнитных, легких примесей и пыли, а также как обеззараживание зернопродуктов. Распределительные клапана с электромагнитами не только обеспечивают равномерную подачу продукта по поперечному сечению, но и выделяют металломагнитные примеси. Кольцевой ротор с установленными внутри него межколечными регуляторами зазора является просеивающим элементом. Продукт, проходя через кольцевой ротор, расслаивается на множество слоев, образуя свободные межзерновые пространства, что способствует эффективному воздействию воздуха на легкие примеси в вертикальной пневмосепарирующей камере.

Вильчатый скребок не только отделяет крупные примеси с поверхности кольцевого ротора, но и предотвращает забивание частиц между кольцами. В случае забивки внутренней части кольцевого ротора предусмотрены очистительные люки.

Совмещение перекидки и первичной переработки зернопродуктов на токах крестьянских и фермерских хозяйствах позволит: производительно эффективно и своевременно производить очистку от примесей, сократить эксплуатационные расходы на приемку и обработку зерна, значительно снизить зараженность зерна вредителями хлебных запасов, создать благоприятные условия для сушки и хранения зерна.

Применение предлагаемой техники и технологии позволяют получить экономический эффект 1,5 млн. тг. при переработке 1000 тонн зерна за счет снижения затрат от совмещения процесса приема и первичной переработки зерна. Использование предлагаемой технологии помимо очистки от вредных (вегетативных, составных частей ворохи зерна и сорных примесей) примесей сопровождается продувкой, т.е. предварительной сушкой, что положительно влияет на сохранность и на обеззараживание вредителей хлебных запасов.

Как известно свежеубранное зерно в северных районах имеют высокую влажность, которая без первичной переработки теряют продовольственную ценность и резко снижают на $20 \%$ стойкость зерна при хранении. Использование предлагаемой технологи помимо очистки от вредных примесей сопровождается предварительной сушкой, что положительно влияет на сохранность и на обеззараживание зерна.

Объектами рынка являются все зернопроизводящие предприятия: крестьянские и фермерские хозяйства, хлебоприёмные и зерноперерабатывающие предприяти: элеваторы, мельницы, комбикормовые, спиртопиво и маслозаводы. В технике и технологии для первичной переработки зернопродуктов востребованы практически все зернопроизводящие и зерноперерабатывающие предприятия РК и стран СНГ. Согласно проведённых экономических расчётов и 
Impact Factor ISRA (India) $\quad=\mathbf{1 . 3 4 4}$

Impact Factor ISI (Dubai, UAE) $=\mathbf{0 . 8 2 9}$

based on International Citation Report (ICR)

Impact Factor GIF (Australia) $\quad \mathbf{0} .356$
Impact Factor JIF

$=\mathbf{1 . 5 0 0}$

Impact Factor SIS (USA)

$=0.912$

Impact Factor РИНЦ (Russia) $=0.179$

Impact Factor ESJI (KZ) $\quad=\mathbf{1 . 0 4 2}$ маркетинговых исследований срок окупаемости стоимости

зернометатель-классификатора составит 5 месяцев. Прогнозируемая потребность
РК в данном оборудовании составляет величину порядка 3,6 тыс. штук.

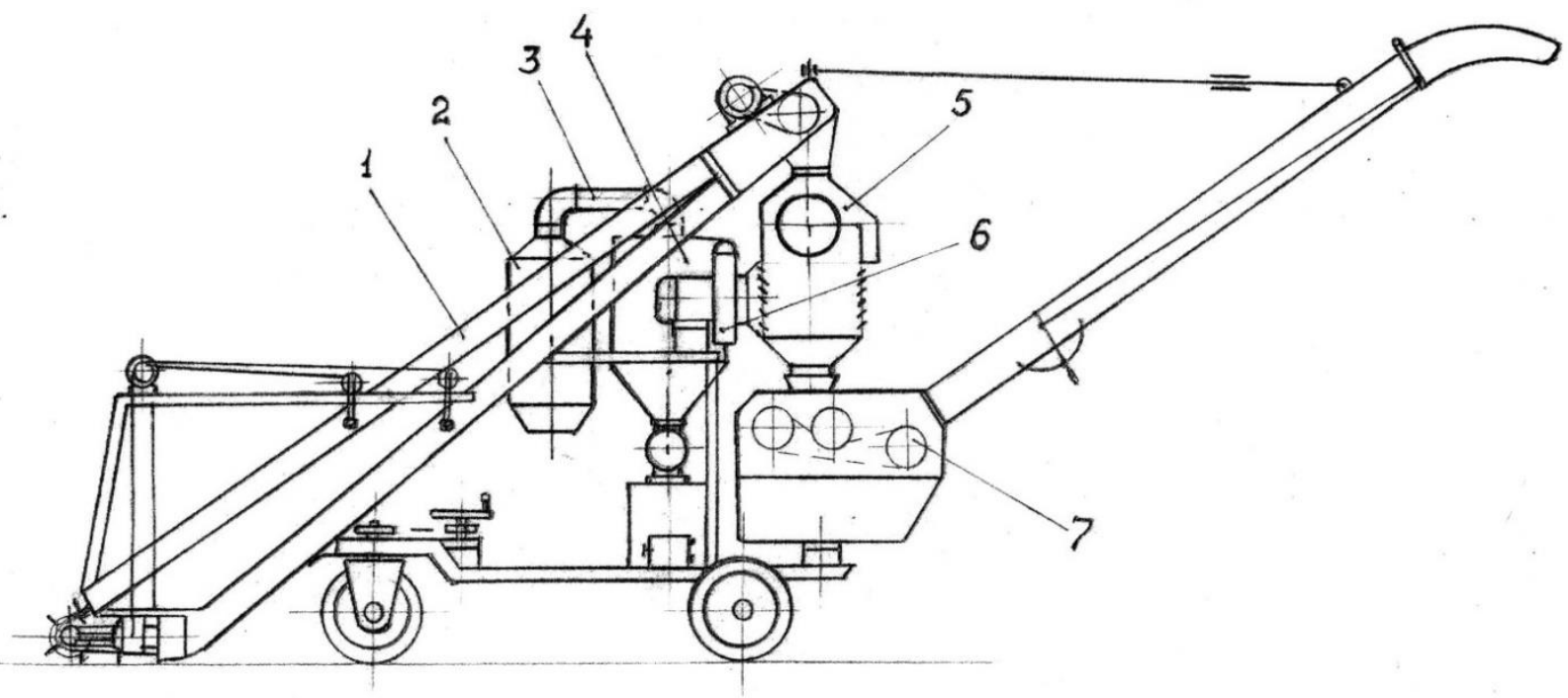

Рисунок 1 - Принципиальная схема зернометателя-классификатора.

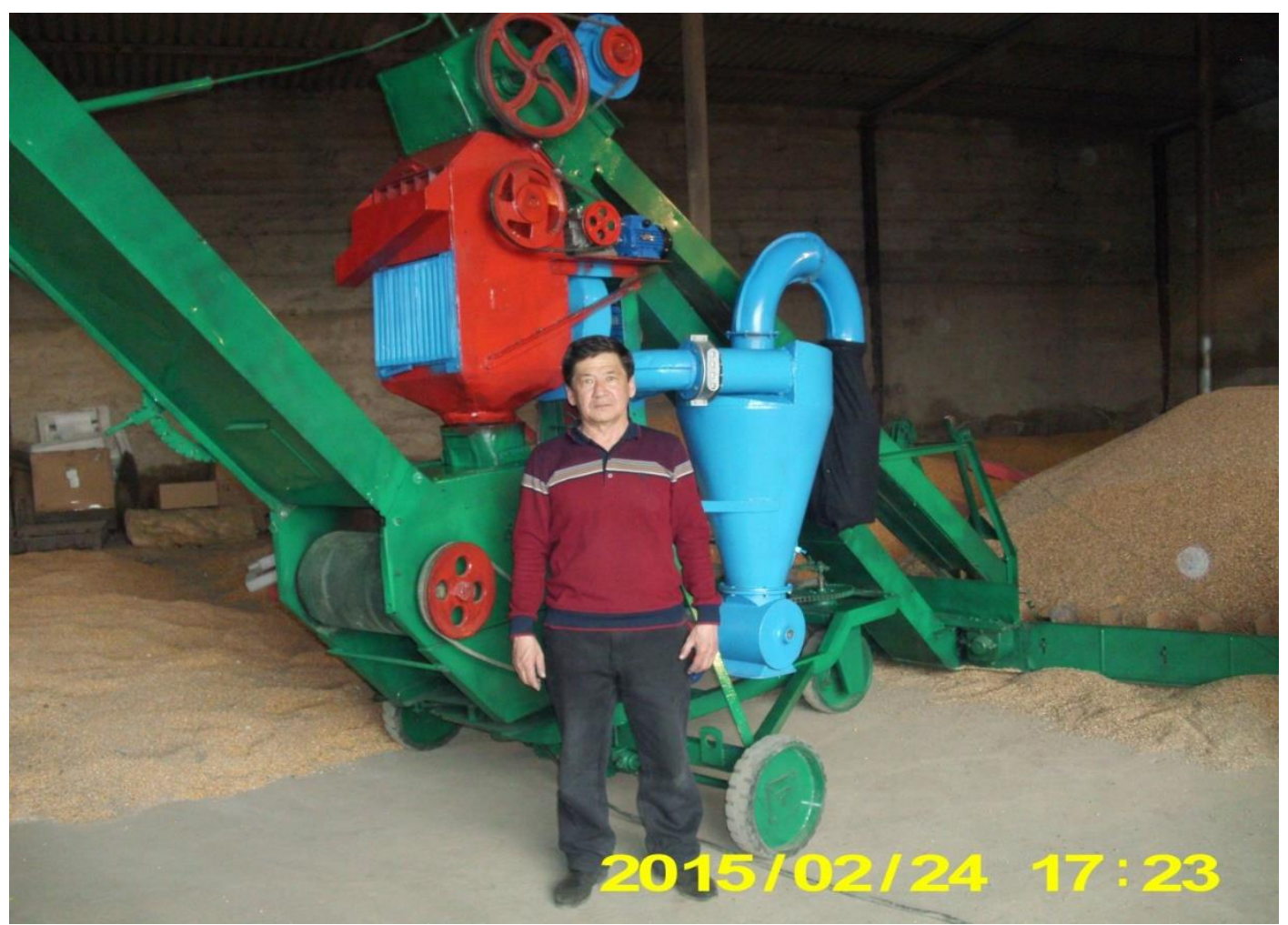

Рисунок 2 - Зернометатель-классификатор.

Инновационная технология относится к области приемки и обработки зерновых продуктов, а зернометатель - классификатор предназначен для перекидки, перегрузки зерна и очистки преимущественно зерна и зернистых продуктов от крупных, металломагнитных, легких примесей и пыли, а также для 
Impact Factor ISRA (India) $\quad=\mathbf{1 . 3 4 4}$

Impact Factor ISI (Dubai, UAE) $=\mathbf{0 . 8 2 9}$

based on International Citation Report (ICR)

Impact Factor GIF (Australia) $\quad \mathbf{0} \mathbf{0 . 3 5 6}$
Impact Factor JIF $\quad=\mathbf{1 . 5 0 0}$

Impact Factor SIS (USA) $\quad=\mathbf{0 . 9 1 2}$

Impact Factor РИНЦ (Russia) $=\mathbf{0 . 1 7 9}$

Impact Factor ESJI (KZ) $\quad=\mathbf{1 . 0 4 2}$ обеззараживания зернопродуктов и предварительной сушки.

Разработана структурная схема ЗК-60. Сущность инновационной технологии поясняется чертежами. На рис. 1 изображена принципиальная схема зернометателя-классификатора, который состоит из зернометателя 3М-60 и пневмороторного классификатора ПРК-60. Основными элементами зернометателя являются скребковый конвейер 1 и ленточный метатель 7. Пневмороторный классификатор включает классификатор 5, всасывающий вентилятор 6, циклон-отделитель 4, воздуховод 3 и рукавный фильтр 2. Классификатор 5 устанавливается между скребковым конвейером 1 и ленточным метателем 7.

Зернометатель-классификатор работает следующим образом. Зерно через скребковый конвейер 1 поступает на классификатор 5, где отделяются металломагнитные и крупные примеси. Легкие примеси, в том числе пыль и насекомые с пневмосепарирующей камеры классификатора 5 отсасываются при помощи вентилятора высокого давления 6 и подаются в циклонотделитель 4, где отделяются легкие примеси, а пылевоздушная смесь через воздуховод 3 направляются в рукавный фильтр, где осаждается пыль. Очищенные от примесей зернопродукты с разгрузочного патрубка классификатора 5 поступают на бесконечную ленту зернометателя 7 .

На рис 2 изображена принципиальная схема пневмороторного классификатора. Классификатор работает следующим образом.
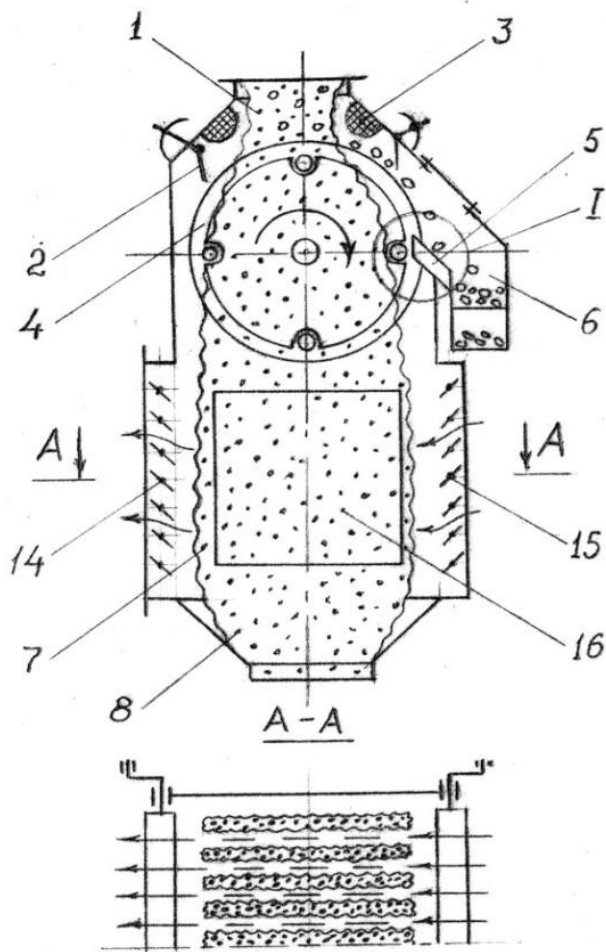

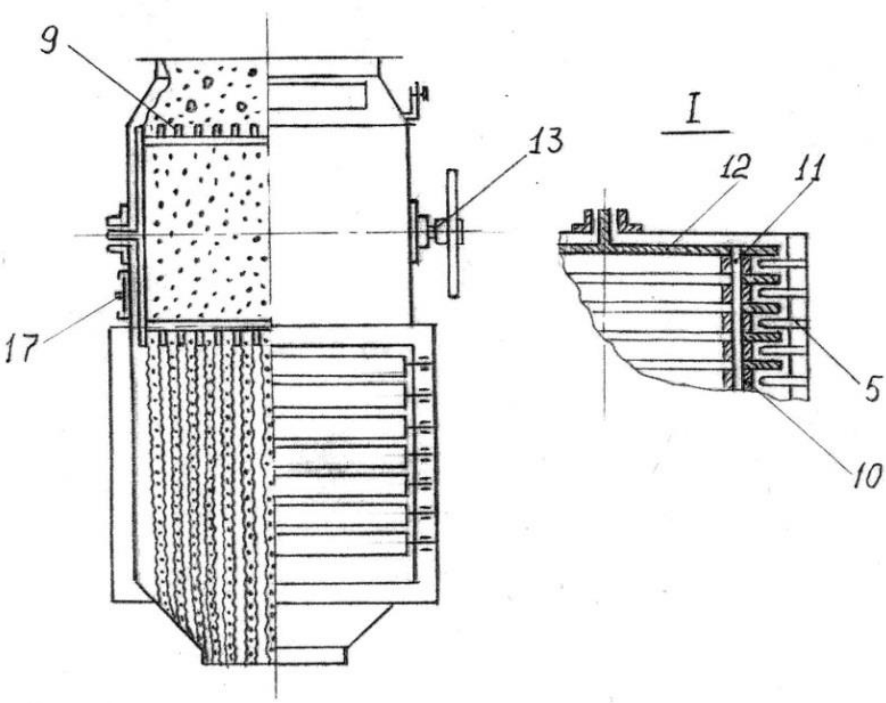

Рисунок 3 - Принципиальная схема пневмороторного классификатора.

Продукт с загрузочного патрубка 1 через распределительные клапана 2 с электромагнитами 3 поступает на вращающийся кольцевой ротор 4. При этом крупные частицы продукта оставаясь на поверхности колец 9 направляются в патрубок 6 для крупных примесей. Застрявшие между кольцами крупные частицы продукта отделяются скребком 5. В случае завивки внутренней части кольцевого ротора предусмотрены очистительные люки 16, расположенные в торцевой части корпуса классификатора на уровне кольцевого ротора. Основная часть продукта, перемещаясь вниз, проходит через продольные зазоры, образованные по окружности кольцами 9, поступает в пневмосепарирующую камеру 7. При этом общий поток продукта расслаивается и распределяется на небольшие слои, между которыми образуются свободные межзерновые пространства (см. Сечение А-А). В вертикальной пневмосепарирующей камере 7 продукт продувается в поперечном направлении воздухом. Воздух при этом входит через регулируемую жалюзийную решетку 15 , пронизывает свободные межзерновые пространства, выделяет легкие частицы, в том числе пыль, насекомые и направляется через всасывающий жалюзийный патрубок 14 
Impact Factor ISRA (India) $\quad=\mathbf{1 . 3 4 4}$

Impact Factor ISI (Dubai, UAE) $=\mathbf{0 . 8 2 9}$

based on International Citation Report (ICR)

Impact Factor GIF (Australia) $=\mathbf{0 . 3 5 6}$
Impact Factor JIF $\quad=\mathbf{1 . 5 0 0}$

Impact Factor SIS (USA) $\quad=\mathbf{0 . 9 1 2}$

Impact Factor РИНЦ (Russia) $=\mathbf{0 . 1 7 9}$

Impact Factor ESJI (KZ) $\quad=\mathbf{1 . 0 4 2}$ вентилятора в циклон-отделитель, где происходит отделение легких частиц от пылевоздушной смеси. Очищенные частицы продукта с пневмосепа-рирующей камеры 7 через разгрузочный патрубок 8 поступают на бесконечную ленту зернометателя.

Пирамидальная форма всасывающих патрубков 14 и регулируемых жалюзийных решеток 5 обеспечивает постоянство скорости воздуха внутри пневмосепарирующей камеры 7, что позволит повысить эффективность процесса разделения продукта от легких примесей и пыли. Для визуального наблюдения за процессом сепарации предусмотрены смотровые окна 16, расположенные в торцевой части пневмосепарирующей камеры.

Нами спроектированы и разработана техническая документация пневмороторного классификатора. Изготовлен экспериментальный образец установки для очистки зерна от крупных и легких примесей.
Проведены

экспериментальные исследования сепаратора на зерне пшеницы и ячменя с производительностью 40-50 тонн/час. В результате исследований установлено, что при расстоянии между кольцами равном 12 мм и при вращении кольцевого ротора с частотой пр $=25$ 45 об/мин крупные примеси, размеры которых превышает зазор между кольцами, полностью отделяются из потока зерна.

Экспериментальные исследования показали, что максимальный коэффициент извлечения легких примесей 78-80\% имеет место при толщине поступающего слоя зерна 30-40 мм, высоте пневмосепарирующей камеры равной 0,5 метра и длине кольцевого ротора равном 0.5 метра. Результат проведенных научных исследований заключается в расширении технологических возможностей пневмороторного классификатора.
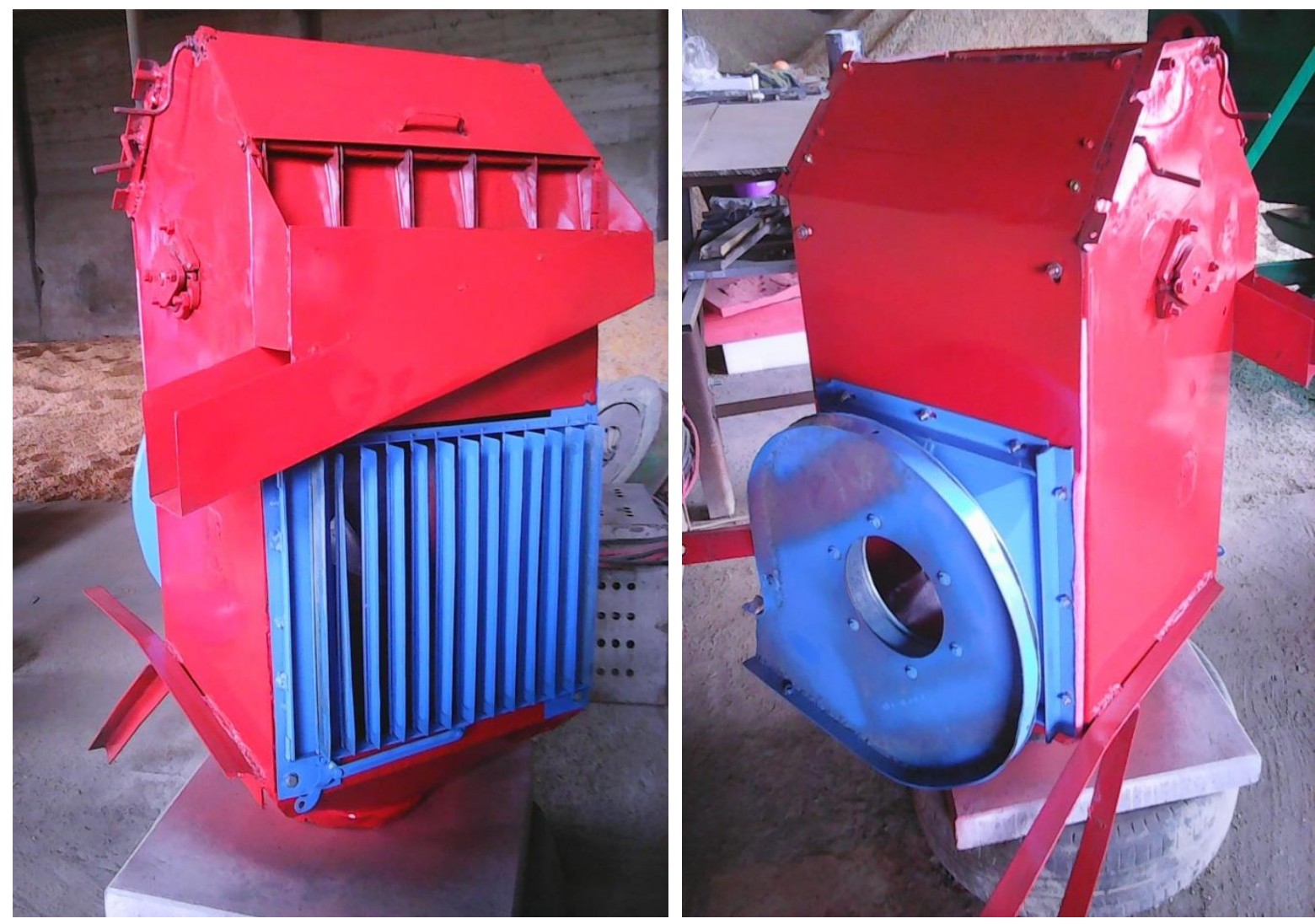

Рисунок 4 - Пневмороторный классификатор.

\section{Основные преимущества инновационной технологии: \\ ЗК-60-зернометатель - классификатор предназначен не только для перекидки, перегрузки зерна, но и для очистки поступающего с поля зернового вороха}

колосовых, крупяных, зернобобовых культур, кукурузы, сорго, подсолнечника, семян рапса от примесей на открытых токах во всех сельскохозяйственных зонах страны.
ISPC Industry \& Technology Europe,

Lyon, France 
3К-60 производит классификацию зерна и зернистых продуктов от крупных, металломагнитных, легких примесей и пыли.

ЗК-60 применяется для обеззараживания зернопродуктов вредителей хлебных запасов (насекомых и клещей).

Использование ЗК-60 позволяет во время очистки зерна производить также его предварительную сушку.

ЗК-60 предназначен для загрузки и выгрузки зерноскладов, погрузки зерна в транспортные средства с высот, механического перелопачивания зерна на открытых площадках во время подвозки зерна от комбайна, формирования буртов из куч зерна, оставляемых транспортными средствами на площадках во время подвозки зерна от комбайна, и сепарации зерна с отделением легких примесей.

Очистка зерна производится на ПРК регулируемым воздушным потоком, что позволяет получить более высокую производительность очистки зерна от легких примесей чем в сепараторах известных производителей.

3К-60 является самоходной, а не стационарной зерноочистительной машиной и не требует дополнительных расходов по введению ее в эксплуатацию (строительства ЗАВов, норий, решения проблем с загрузкой зерна в зерноочистительную машину, отвода очищенного по фракциям продовольственного и фуражного зерна и т. д. ).
ЗК-60

является

мобильной

зерноочистительной машиной и может легко быть перевезена на другой ток, зерносклад или же вообще в другое хозяйство. Это особенно актуально для хозяйств, у которых несколько зернотоков или зерноскладов, так как использование ЗК-60 позволяет сэкономить огромные деньги на строительстве нескольких ЗАВов или закупке других стационарных зерноочистительных машин.

Высокая производительность певичной очистки зерна от крупных, легких, металломагнитных примесей и пыли 60 т/ч.

Минимальные расходы электроэнергии на первичную переработку зерна в ЗК-60$0,55 \kappa \mathrm{Bт} /$ час на 1 т.

ЗК-60 в отличие от других зерноочистительных машин может самостоятельно без помощи зернометателей, погрузчиков, норий и т. п. производить загрузку зерна в кузов автомашины или прицеп.

В процессе эксплуатации 3К-60 не требует дорогостоящего сервисного обслуживания.

3К-60 являются исключительно надежными зерноочистительными машинами, но даже в случае поломки запчасти можно приобрести повсеместно.

Наличие know-how: Совмещение в одном мобильном устройстве перегрузочных операции с технологическими, как очистка зерна от крупных, металломагнитных, легких примесей и пыли, а также как обеззараживание и предварительная сушка зернопродуктов.

\section{References:}

1. (2009) Ustroystvo dlya ochistki produktov ot legkikh primesey $\mathrm{v}$ punkte zagruzki konveyra. Innovatsionnyy patent na izobretenie, AS №65463 ot 23.06.2009.

2. (2009) Pnevmorotornyy klassifikator. Innovatsionnyy patent RK na izobretenie, AS №65792 ot 04.08.2009.

3. (2010) Patent na izobretenie. Ustanovka dlya ochistki zernoproduktov ot krupnykh i legkikh primesey. NIIS MYuRK, ot 01.06.2010, №2010/0724.1. Avt. svid. № 68849.

4. (2010) Patent na izobretenie. Pnevmaticheskiy klassifikator produktov $\mathrm{V}$ punkte razgruzki konveyera. NIIS MYuRK, ot 01.06.2010, №2010/0722.1. Avt. svid. № 68853.

5. (2010) Zernometatel'-klassifikator. AS № 70124 ot 01.06 .2010 . innovatsionnyy patent RK №24531.
6. Demskiy AB, Veden'ev VF (1978) Osnovnye napravleniya sovershenstvovaniya pnevmoseparatsionnogo zernoochistitel'nogo oborudovaniya. - Moscow: TsNIITEILegpishchemash, 1978. - 73 p.

7. Devidson I, Kharrison D (1974) Psevdoozhizhenie. - Moscow, Khimiya, -430 p.

8. Zlochevskiy VL (1986) Intensifikatsiya protsessa aerodinamicheskogo razdeleniya zernovykh materialov. - Dis. doktora tekhn. nauk. - Novosibirsk, 1986, - 473 p.

9. Karpov BA (1987) Tekhnologiya posleuborochnoy obrabotki khraneniya zerna. Moscow: Agropromizdat, 1987. - 288 p.

10. Punkov SP, Iztaev AI (1982) Posleuborochnaya obrabotka zerna.- Alma-Ata : Kaynar, - 167 p.

11. Razvorotnev AS (1987) Obespylivanie zerna pri priemke. Mukomol'no-elevatornaya promyshlennost' i kombikormovaya promyshlennost'. - 1987. - № 4. - pp. 19 - 21 . 